\title{
Lipase-catalyzed synthesis of fatty acid esters of
}

trisaccharides

Jose L. Gonzalez-Alfonso ${ }^{a}$, Leticia Casas-Godoy ${ }^{b}$, Javier Arrizon ${ }^{b}$, Daniel ArrietaBaez $^{\mathrm{c}}$, Antonio O. Ballesteros ${ }^{\mathrm{a}}$, Georgina Sandoval ${ }^{\mathrm{a}}$ and Francisco J. Plou ${ }^{\mathrm{a},{ }^{*}}$

${ }^{a}$ Instituto de Catálisis y Petroleoquímica, CSIC, 28049 Madrid, Spain

${ }^{\mathrm{b}}$ Centro de Investigación y Asistencia en Tecnología y Diseño del Estado de Jalisco A.C., Av. Normalistas 800, Col. Colinas de la Normal, C.P. 44270 Guadalajara, Jal., Mexico

${ }^{c}$ Instituto Politécnico Nacional - CNMN, Calle Luis Enrique Erro s/n, Unidad Profesional Adolfo López Mateos, Col. Zacatenco, México D.F. CP 07738, Mexico

\section{Abstract}

Carbohydrate fatty acid esters have a broad spectrum of applications in the food, cosmetic and pharmaceutical industries. The enzyme-catalyzed acylation is significantly more selective than the chemical process and is carried out at milder conditions. Compared with mono- and disaccharides, the acylation of trisaccharides has been less studied. However, trisaccharide esters display notable bioactive properties, probably due to the higher hydrophilicity of the sugar head group. In this chapter, we describe the acylation of two trisaccharides, maltotriose and 1-kestose, catalyzed by different immobilized lipases, using vinyl esters as acyl donors. To illustrate the potential of such compounds, the antitumor activity of 6"-O-palmitoyl-maltotriose is shown.

\section{Key Words}

Lipases, acylation, sugar esters, transesterification, regioselectivity, surfactants, maltotriose, 1-kestose. 


\section{Introduction}

The industrial synthesis of sugar esters is usually performed at high temperatures and catalyzed by basic compounds, which give rise to coloured side-products with low selectivity [1]. In fact, the regioselective acylation of carbohydrates is difficult to achieve due to the presence of multiple hydroxyl groups with similar reactivity [2]. In contrast with the chemical synthesis, the enzyme-catalyzed processes are notably more selective and take place at milder conditions [3,4]. Lipases and proteases are typically the most useful enzymes for this purpose [5].

A medium in which a polar reagent (the sugar) and a non-polar fatty acid donor are soluble is required for enzymatic acylation of carbohydrates. In addition, this medium must be compatible with enzyme activity. We developed a strategy based on the use of a mixture of a tertiary alcohol (2-methyl-2-butanol) and a polar solvent (DMSO), which was successfully applied to the synthesis of monosaccharide (glucose) esters [6], disaccharide (e.g. sucrose, maltose, leucrose) esters [7-10] and even trisaccharide (maltotriose) esters [11].

Most of the research on sugar ester synthesis has been focused on monosaccharides and disaccharides [1,12]. In contrast, the acylation of trisaccharides and higher oligosaccharides has been scarcely studied [13-18]. The main advantage of trisaccharide and oligosaccharide esters, regarding simple sugars derivatives, lies in their significantly higher aqueous solubility, as a consequence of the increased hydrophilicity of the sugar head group [19].

Interestingly, bioactive properties of trisaccharide esters are very promising. It is worth mentioning their antimicrobial effect against microorganisms involved in food spoilage [20], their anticariogenic effect [21] 
and anti-cancer properties [11]. Due to their low toxicity, non-antigenicity, bioactivity and biodegradability, trisaccharide esters have a wide range of potential applications $[1,22]$.

In this work, we describe the synthesis of several fatty acid esters of two trisaccharides (see Fig. 1), maltotriose [8] and 1-kestose [15], by a transesterification strategy with vinyl esters. Different immobilized lipases were employed as biocatalysts.

\section{Materials}

\subsection{Reaction components}

1. Carbohydrates: 1-Kestose and maltotriose (Sigma-Aldrich).

2. Acyl donors: Vinyl laurate, vinyl myristate, vinyl palmitate and vinyl stearate ( $\mathrm{TCl}$, Japan).

3. Biocatalysts:

- Immobilized lipase from Thermomyces lanuginosus (formerly Humicola lanuginosa) immobilized on Celite (diatomaceous earth, 30-80 mesh, BDH, England) or granulated with silica (Lipozyme TL-IM, Novozymes A/S, Denmark) for maltotriose acylation.

- Immobilized lipase from Candida antarctica B (Lipozyme 435, Biotecsa, Mexico) for 1-kestose reaction.

4. Solvents: Hexane, n-heptane, methanol and 2-methyl-2-butanol (SigmaAldrich); acetone (Scharlab); dimethyl sulfoxide (DMSO) (Merck). To assure anhydrous conditions, all solvents were dried in molecular sieves (3 $\AA$, $1.6 \mathrm{~mm}$, Sigma Aldrich) at least for $24 \mathrm{~h}$.

\subsection{HPLC Components}


1. Pump: SP8810 (Spectra-Physics) or ProStar 230 (Varian).

2. Oven: The column temperature was kept at $40^{\circ} \mathrm{C}$.

3. Column: Nucleosil $100-\mathrm{C} 18(250 \times 4.6 \mathrm{~mm}, 5 \mu \mathrm{m})$ for maltotriose esters and Zorbax SB-C18 (250 x $4.6 \mathrm{~mm}, 5 \mu \mathrm{m})$ for 1-kestose esters.

4. Detectors: Identification of trisaccharide esters was performed using a refractive index detector (Shoedex, Showa Denka K.K.) or an evaporative light-scattering detector (PL-ELS 2100, Varian). The latter was adjusted to $1.6 \mathrm{~L} / \mathrm{min}$ nitrogen flow rate, $60^{\circ} \mathrm{C}$ nebulization temperature, $105^{\circ} \mathrm{C}$ evaporation temperature (see Note 1).

5. Software: Integration was carried out using the Varian Star 4.0 software.

\subsection{Electrospray ionization (ESI) analysis}

1. Equipment: Bruker micrOTOF-Q II (Bruker Daltonics, Bremen, Germany).

2. Samples preparation: Samples were dissolved in methanol and were injected directly to the spectrometer.

3. Analysis conditions: Positive ion mode [ESI+], capillary potential of -4.5 $\mathrm{kV}$, dry gas temperature $200^{\circ} \mathrm{C}$ and the drying gas flow $4 \mathrm{~L} / \mathrm{min}$. Total ion chromatograms from $\mathrm{m} / \mathrm{z} 500$ to 3000 .

4. Software: MS data was processed using Compass TM software (Bruker Daltonics).

\subsection{Silica gel chromatography}

1. For the purification of maltotriose derivatives, mix silica gel 60 (0.06-0.2 $\mathrm{mm}, 70-230$ mesh, Merck) with the eluent (see the corresponding section) and let humidify for 5 min (under stirring). 
2. Pour the silica into the column and let the mobile phase pass through it until obtaining the desired height, leaving $2 \mathrm{~cm}$ of mobile phase at the column head.

3. Evaporate the solvent in the reaction mixture using a rotary evaporator. Then, add silica gel and $5 \mathrm{ml}$ of mobile phase. Evaporate the mixture, again.

4. Put the dried silica with reaction mixture into the column and start adding the mobile phase.

5. Take out aliquots $(5 \mathrm{ml})$ and follow the progress of the purification by Thin Layer Chromatography (TLC).

\subsection{Thin Layer Chromatography}

1. Cut silica plates (Silica gel/TLC cards, $10 \times 20 \mathrm{~cm}$, with fluorescent indicator $254 \mathrm{~nm}$, layer thickness $0.2 \mathrm{~mm}$ ) into $10 \times 4 \mathrm{~cm}$ plates.

2. Add $10 \mathrm{ml}$ of mobile phase (see corresponding section) in the TLC cuvette.

3. Mark the application points on the plate and add $1 \mu$ of the aliquot in each well. Let it dry and introduce the plate in the TLC cuvette.

4. Let the mobile phase elute until it is almost at the end of the plate.

5. Stain the plate with Bial's reagent diluted with 4 volumes of ethanol (see Note 2).

6. Dry and heat the plate at $120^{\circ} \mathrm{C}$ for 5 minutes.

\section{Methods}

\subsection{Acylation of maltotriose}

1. Dissolve maltotriose (303 mg, $0.6 \mathrm{mmol})$ in $5 \mathrm{~mL}$ of DMSO. 
2. Add 2-methyl-2-butanol to $25 \mathrm{~mL}$ final volume $(20 \% \mathrm{DMSO}$ in the reaction mixture, see Note 3 ).

3. For immobilisation of lipase from Thermomyces lanuginosus in Celite, the $\mathrm{pH}$ of commercial Lipolase $100 \mathrm{~L}$ solution $(100 \mathrm{ml})$ was adjusted to 7.0. The support $(8 \mathrm{~g})$ was added and the suspension stirred for $30 \mathrm{~min}$ at $4^{\circ} \mathrm{C}$. Then, $200 \mathrm{ml}$ of cold acetone $\left(0^{\circ} \mathrm{C}\right)$ were slowly added with stirring. The immobilised enzyme was filtered, washed with acetone, dried in vacuo, and stored at $0^{\circ} \mathrm{C}$.

4. Weight $2.5 \mathrm{~g}$ of biocatalyst (Thermomyces lanuginosus lipase immobilised on Celite or granulated with silica) and $2.5 \mathrm{~g}$ of $3 \AA$ molecular sieves to maintain anhydrous conditions (see Note 4).

5. Keep the suspension for 30 minutes at $40 \stackrel{\circ}{\mathrm{C}}$ with orbital stirring (see Note 5).

6. Add the fatty acid vinyl ester $(7.5 \mathrm{mmol})$ and incubate the mixture for $24 \mathrm{~h}$ at $40{ }^{\circ} \mathrm{C}$ (see Note 6$)$.

7. Monitor the reaction by thin layer chromatography (TLC) on silica gel 60 plates (Merck) (see section 2.5) using chloroform/methanol 4:1 (v/v) as eluent.

8. Cool, filter and wash the solid phase with 3 volumes of 2-methyl-2butanol.

9. Precipitate maltotriose ester in the liquid phase adding between 2.5 and 10 volumes of $n$-heptane.

10. Filter the white solid. 
11. Recrystallize the reaction product in acetone and dry the product in vacuo. Calculate the yield based on the weight of isolated ester (see Table 1).

12. Analyze the conversion (referred to the initial amount of maltotriose) and the ratio monoester/diester (see Table 1) by reverse-phase HPLC (see section 2.2). The specific conditions of mobile phase and flow rate are:

- Mobile phase 85:15 (v/v) methanol / $\mathrm{H}_{2} \mathrm{O}$ and flow rate $1.5 \mathrm{~mL} / \mathrm{min}$ for esters of lauric and myristic acids.

- Mobile phase 95:5 (v/v) methanol / $\mathrm{H}_{2} \mathrm{O}$ and flow rate of $1.1 \mathrm{~mL} / \mathrm{min}$ for esters of palmitic and stearic acids.

13. The isolated products were fully characterized by spectroscopic techniques (NMR, FTIR and high resolution MS)

14. NMR analyses determined that the acylation took place in the $6-\mathrm{OH}$ of the glucose moiety at the non-reducing end (see Fig. 2 for reaction scheme of maltotriose monolaurate synthesis).

15. To determine whether these compounds could exert a potential pharmacological effect, their cytotoxic activities against two human cancer cell lines, Hep-G2 and HeLa, were studied by means of the colorimetric MTT test [23] (see Note 7). 6"-O-palmitoyl-maltotriose treatment resulted in a dose-dependent decrease of cell viability of both Hep-G2 and HeLa cells (see Fig. 3). Curve analysis allowed graphic estimation of the concentration causing 50\% cell growth inhibition (IC50). The IC50 values for 6"-O-palmitoylmaltotriose against the growth of HepG2 and HeLa cancer cell lines were 2.3 $\mu \mathrm{M}$ and $3.6 \mu \mathrm{M}$, respectively. 


\subsection{Acylation of 1-kestose}

1. Weigh 1-kestose $(320 \mathrm{mg}, 0.63 \mathrm{mmol})$ and add vinyl laurate $(1.040 \mathrm{ml}, 4$ $\mathrm{mmol}$ ) to a volume of $10 \mathrm{ml}$ of hexane (in $15 \mathrm{~mL}$ thermostated-capped cylindrical glass tube) with $10 \%(\mathrm{w} / \mathrm{v})$ of activated molecular sieves and 10\% (w/v) of Lipozyme 435 B from Candida antarctica (see Note 8).

2. Put the glass tube under orbital agitation at $60^{\circ} \mathrm{C}$.

3. Follow the progress of the reaction for $96 \mathrm{~h}$ with analytical HPLC (see section 2.2). The mobile phase was 90:10 (v/v) methanol / $\mathrm{H}_{2} \mathrm{O}$ and the flow rate $0.6 \mathrm{~mL} / \mathrm{min}$.

4. Perform a liquid-liquid extraction to isolate the product. The carbohydrate fatty acid ester will be in the organic phase.

5. Remove the solvent by speed-vac evaporation.

6. Dissolve the sample in methanol and inject it directly to the spectrometer ESI-MS. The sugar molecules usually form singly-charged ions by adding $\mathrm{Na}^{+}$. For example, 1-kestose without acylation produces the peak $[\mathrm{M}+\mathrm{Na}]^{+}$ at $\mathrm{m} / \mathrm{z}$ of 527.2 (see Fig. 4A). The enzymatic acylation reaction of 1 kestose produced a major adduct peak at $\mathrm{m} / \mathrm{z}$ of 709.5 , corresponding to monolaurate (see Note 9), and a second adduct peak at $\mathrm{m} / \mathrm{z} 891.5$, corresponding to dilaurate (see Fig. 4B).

\section{Notes}

1. The chromatographic detection of vinyl esters can be performed with an absorbance or photodiode array detector. Quantification can be carried out at $216 \mathrm{~nm}$. 
2. Bial's reagent is prepared mixing $0.4 \mathrm{~g}$ orcinol, $200 \mathrm{ml}$ of concentrated hydrochloric acid and $0.5 \mathrm{ml}$ of a $10 \%$ ferric chloride $(\mathrm{w} / \mathrm{v})$ solution.

3. Although the use of $5 \%$ DMSO instead of $20 \%$ DMSO in the acylation process gives rise to a higher conversion (about 3.5 -fold compared with $20 \%$ DMSO, see Table 1), the presence of $10 \%$ diesters in the final product must be considered if the objective is to obtain a pure monoester.

4. The presence of water during the reaction decreases the reaction yield. This is due to the capability of the enzyme to use water as acceptor and hydrolyze the acyl donor (releasing the corresponding acid) and the obtained product (reversing the reaction). Most of the water in the reaction mixture comes from the biocatalyst and the solvents. Thus, it is advisable to dry the solvents using $3 \AA$ molecular sieves and also to include molecular sieves in the reaction mixture. It is also possible to increase the reaction yield by dehydration of the biocatalyst in a vacuum desiccator overnight.

5. Avoid the use of magnetic stirrers. Enzymes are unstable in the presence of this kind of stirring. It is preferable to use orbital shakers to carry out the reaction.

6. Vinyl esters were chosen as acyl donors since the equilibrium can be shifted towards the ester formation (the resulting vinyl alcohol tautomerizes towards low-boiling-point acetaldehyde). Using ethyl esters as acyl donors, both the conversion and reaction rate are one order of magnitude lower than that obtained with the corresponding vinyl ester.

7. HepG2 is a cell line derived from a human hepatoma and is representative of a differentiated tumor cell. HepG2 shows a limited, but measurable, hepatic functionality. HeLa, on the other hand, is a rather undifferentiated 
cell line with notable cell growth capability. Results are the average of three different experiments and are expressed as the percentage of cell growth inhibition compared with a control in absence of ester.

8. Lipozyme 435 B displays a hydrolytic activity towards tripropionin around $1700 \mathrm{U} / \mathrm{g}$. It is advisable to check this activity before starting the synthesis. The hydrolytic activity is measured titrimetrically at $\mathrm{pH} 8.0$ and $30^{\circ} \mathrm{C}$ using a pH-stat (Mettler, Model DL 50). The reaction mixture contains tripropionin (0.4 ml, final concentration $105 \mathrm{mM})$, acetonitrile $(0.6 \mathrm{ml})$ and buffer $(19 \mathrm{ml}$, Tris- $\mathrm{HCl} 1 \mathrm{mM}, \mathrm{NaCl} 0.1 \mathrm{M}, \mathrm{pH} 8.0$ ). The $\mathrm{pH}$ is automatically kept at 8.0 with $0.1 \mathrm{~N} \mathrm{NaOH}$ as titrant. One enzyme unit $(U)$ corresponds to the formation of $1 \mu \mathrm{mol}$ of fatty acid per min.

9. The monolaurate synthesized in this work is expected to be acylated at the terminal fructose moiety of 1 -kestose, due to less steric hindrance in the active site of the lipase. It has been previously reported that $C$. antarctica lipase $\mathrm{B}$ displays a notable regiospecificity to acylate the $6-\mathrm{OH}$ of fructose in contrast with the other primary hydroxyl 1-OH [4].

\section{Acknowledgements}

We thank CONACYT (Mexico) and Kuragobiotek Holdings for the economic support received. The projects BIO2013-48779-C4-1-R and BIO201676601-C3-1-R from the Spanish Ministry of Economy and Competitiveness also supported this research. 


\section{References}

1. Neta NS, Teixeira JA, Rodrigues LR (2015) Sugar ester surfactants: Enzymatic synthesis and applications in food industry. Critical Reviews in Food Sci Nutrition 55:595-610

2. Polat T, Linhardt RJ (2001) Syntheses and applications of sucrose-based esters. Journal of Surfactants and Detergents 4:415-421

3. In SY, Sang JP, Hyon HY (2007) Enzymatic synthesis of sugar fatty acid esters. Journal of Industrial and Engineering Chemistry 13:1-6

4. Plou FJ, Cruces MA, Ferrer M et al (2002) Enzymatic acylation of di- and trisaccharides with fatty acids: choosing the appropriate enzyme, support and solvent. Journal of Biotechnology 96:55-66

5. Yang Z, Huang ZL (2012) Enzymatic synthesis of sugar fatty acid esters in ionic liquids. Catalysis Science and Technology 2:1767-1775

6. Voutsas EC, Tsavas P, Magoulas K et al (2002) Solubility measurements of fatty acid glucose and sucrose esters in 2-methyl-2-butanol and mixtures of 2-methyl-2-butanol with dimethyl sulfoxide. Journal of Chemical and Engineering Data 47:1517-1520

7. Ferrer M, Cruces MA, Bernabe M et al (1999) Lipase-catalyzed regioselective acylation of sucrose in two-solvent mixtures. Biotechnology and Bioengineering 65:10-16

8. Ferrer M, Cruces MA, Plou FJ et al (2000) A simple procedure for the regioselective synthesis of fatty acid esters of maltose, leucrose, maltotriose and n-dodecyl maltosides. Tetrahedron 56:4053-4061

9. Ferrer M, Soliveri J, Plou FJ et al (2005) Synthesis of sugar esters in solvent mixtures by lipases from Thermomyces lanuginosus and Candida antarctica 
B, and their antimicrobial properties. Enzyme and Microbial Technology $36: 391-398$

10. Reyes-Duarte D, Lopez-Cortes N, Ferrer et al (2005) Parameters affecting productivity in the lipase-catalysed synthesis of sucrose palmitate. Biocatalysis and Biotransformation 23:19-27

11. Ferrer M, Perez G, Plou FJ et al (2005) Antitumour activity of fatty acid maltotriose esters obtained by enzymatic synthesis. Biotechnology and Applied Biochemistry 42:35-39

12. Ye R, Hayes DG (2014) Recent progress for lipase-catalysed synthesis of sugar fatty acid esters. Journal of Oil Palm Research 26:355-365

13. Riva S, Chopineau J, Kieboom APG et al (1988) Protease-catalyzed regioselective esterification of sugars and related compounds in anhydrous dimethylformamide. Journal of the American Chemical Society 110:584-589

14. Pérez-Victoria I, Morales JC (2006) Complementary regioselective esterification of non-reducing oligosaccharides catalyzed by different hydrolases. Tetrahedron 62:878-886

15. Casas-Godoy L, Arrizon J, Arrieta-Baez D et al (2016) Synthesis and emulsifying properties of carbohydrate fatty acid esters produced from Agave tequilana fructans by enzymatic acylation. Food Chemistry 204:437-443

16. van Kempen SEHJ, Boeriu CG, Schols HA et al (2013) Novel surface-active oligofructose fatty acid mono-esters by enzymatic esterification. Food Chemistry 138:1884-1891.

17. Pérez-Victoria I, Morales JC (2006) Regioselectivity in acylation of oligosaccharides catalyzed by the metalloprotease thermolysin. Tetrahedron 62:2361-2369. 
18. Liu K-J (2017) Enzymatic synthesis of isomaltotriose palmitate and evaluation of its emulsifying property. Enzyme and Microbial Technology 101:51-56.

19. Ferrer M, Comelles F, Plou FJ et al (2002) Comparative surface activities of di- and trisaccharide fatty acid esters. Langmuir 18:667-673

20. Garofalakis G, Murray BS, Sarney DB (2000) Surface activity and critical aggregation concentration of pure sugar esters with different sugar headgroups. Journal of Colloid and Interface Science 229:391-398

21. Devulapalle KS, Gomez de Segura A, Ferrer M et al (2004) Effect of carbohydrate fatty acid esters on Streptococcus sobrinus and glucosyltransferase activity. Carbohydrate Research 339:1029-1034

22. Ferrer M, Golyshin P, Timmis KN (2003) Novel maltotriose esters enhance biodegradation of Aroclor 1242 by Burkholderia cepacia LB400. World Journal of Microbiology \& Biotechnology 19:637-643

23. Mosmann T (1983) Rapid colorimetric assay for cellular growth and survival: application to proliferation and cytotoxicity assays. Journal of Immunological Methods 65:55-63 
Table 1. Acylacion of maltotriose with vinyl esters of different chain length in mixtures 2-methyl-2-butanol/DMSO catalyzed by $T$. lanuginosus lipase immobilized in Celite. Table adapted with permission from reference [8].

\begin{tabular}{llll}
\hline Acyl donor & $\begin{array}{l}\text { Percentage } \\
\text { of DMSO }\end{array}$ & $\begin{array}{l}\text { Conversion }(\%)^{\mathbf{a}} \\
\text { Monoester / Diester }\end{array}$ & Yield (\%) $^{\mathbf{b}}$ \\
\hline Vinyl laurate & 5 & $88 / 10$ & 74 \\
Vinyl laurate & 20 & $25 /<1$ & 21 \\
Vinyl myristate & 20 & $32 /<1$ & 26 \\
Vinyl palmitate & 20 & $33 /<1$ & 28 \\
Vinyl stearate & 20 & $38 /<1$ & 27 \\
\hline
\end{tabular}

${ }^{a}$ Determined by HPLC (referred to the initial concentration of maltotriose)

${ }^{\mathrm{b}}$ Referred to the weight of isolated product 


\section{Figure legends}

Fig. 1. Structure of maltotriose and 1-kestose.

Fig. 2. Reaction scheme for the synthesis of 6"-O-palmitoyl-maltotriose catalyzed by Thermomyces lanuginosus lipase.

Fig. 3. Cell viability of several cellular models after exposure to 6"-O-palmitoylmaltotriose. Hep-G2 (•) and HeLa (०) cell lines were exposed to monoester for $24 \mathrm{~h}$, and cell viability was measured by the MTT test after a further $24 \mathrm{~h}$ treatment. Each point represents the average of the data derived from three independent experiments \pm standard deviation. Figure adapted with permission from reference [11].

Fig 4. (A) ESI-MS in positive mode of 1-kestose ( $\mathrm{m} / \mathrm{z}$ value of 527.2$)$ and (B) mono and diacylated 1-kestose with vinyl laurate $(\mathrm{m} / \mathrm{z}$ values of 709.4 and 891.5, respectively). Figure adapted with permission from reference [15]. 
Fig. 1

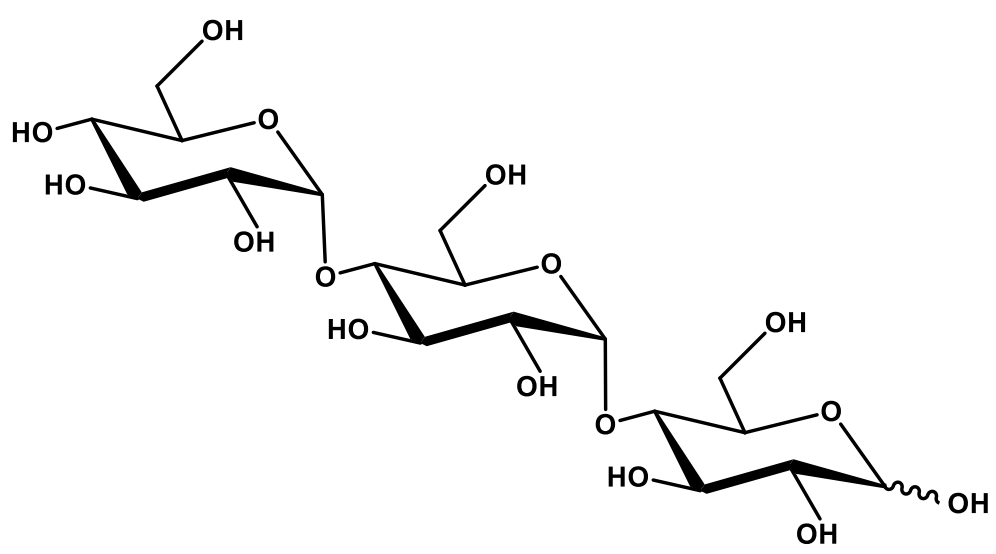

Maltotriose

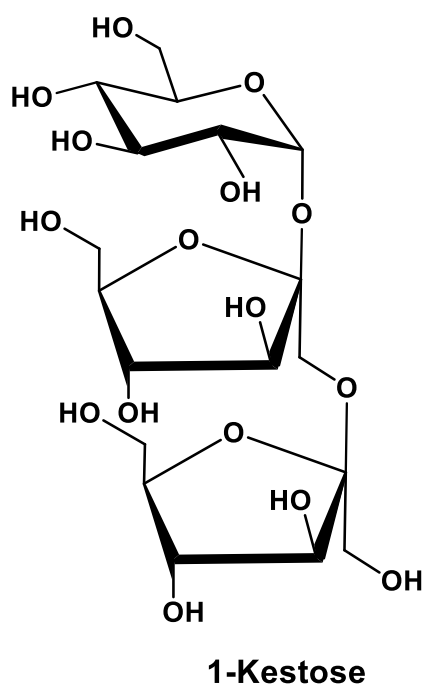


Fig. 2
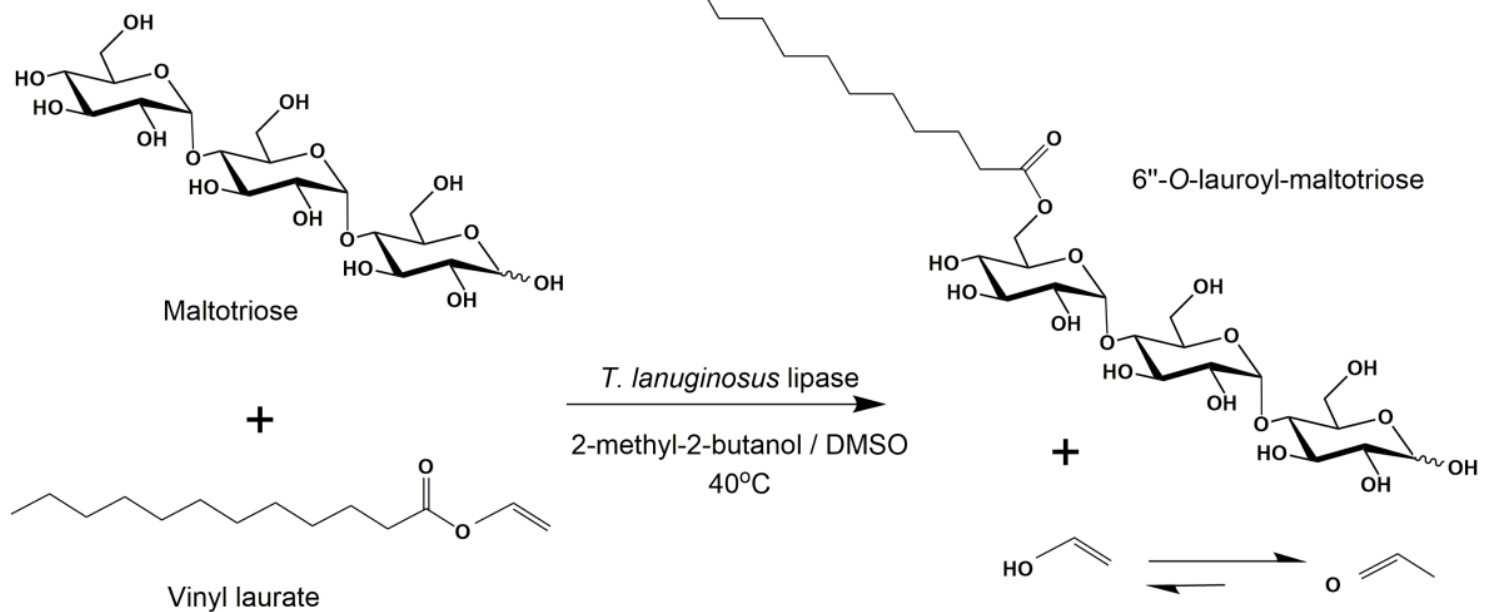

Vinyl alcohol

Acetaldehyde 
Fig. 3

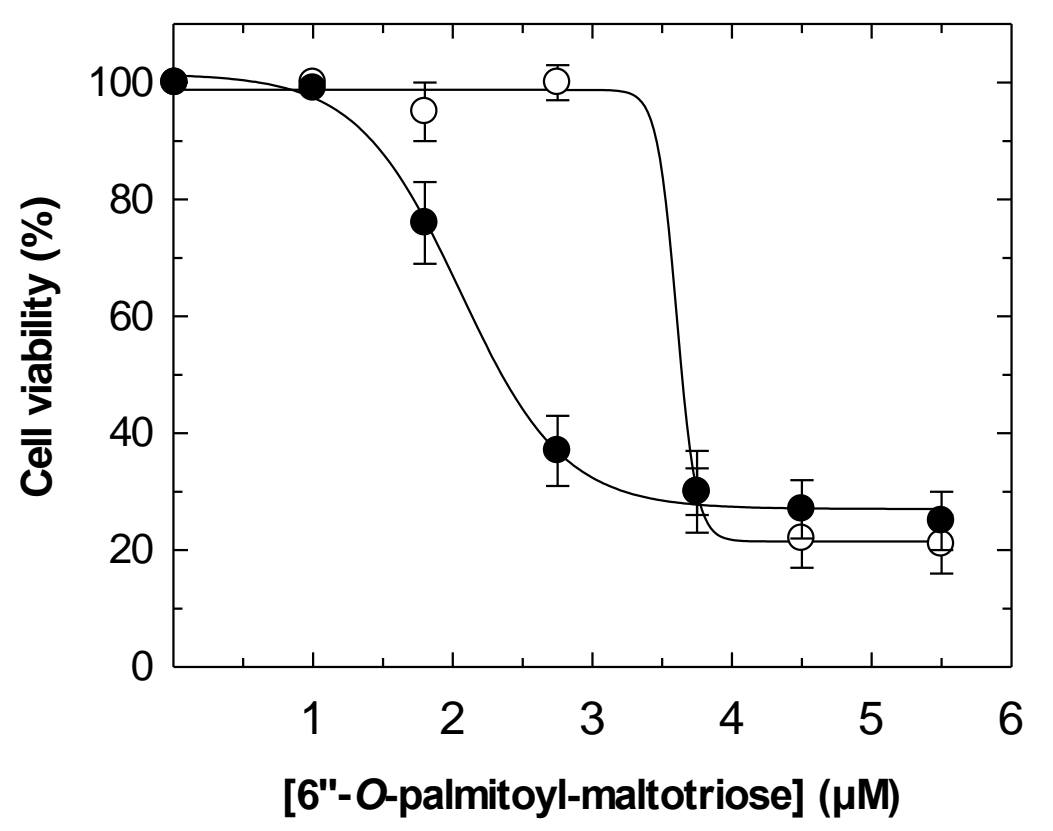


Fig. 4

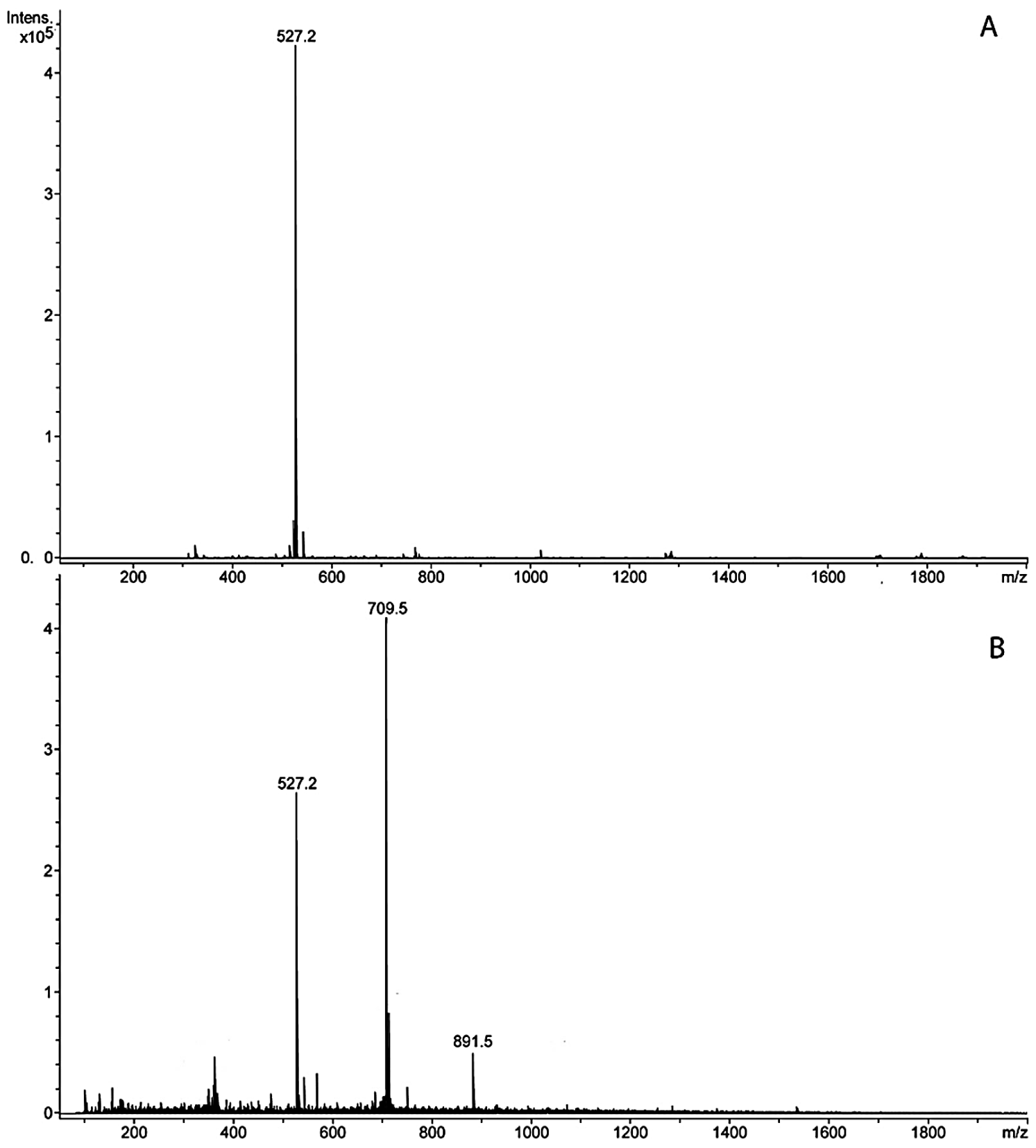

